\title{
Development of Building Fire Control and Management System in BIM Environment
}

\author{
Yan-Chyuan SHIAU ${ }^{1}$, Yi-Yin TSAI ${ }^{2}$, Jui-Ying HSIAO ${ }^{1}$, Chong-Teng CHANG ${ }^{1}$ \\ ${ }^{1}$ Department of Construction Management, Chung Hua University, \\ 707, WuFu Rd., Sec. 2, Hsinchu, 300, Taiwan, \\ ycshiau@ms22.hinet.net, jui.ying.hsiao@gmail.com,m09816011@chu.edu.tw \\ 2 Department of Architecture and Urban Planning, Chung Hua University, \\ 707, WuFu Rd., Sec. 2, Hsinchu, 300, Taiwan, \\ yiyint@chu.edu.tw
}

\begin{abstract}
The quality of fire and disaster prevention is an important aspect within buildings and architectural structures because it directly affects the life, property, and safety of residents. By combining building fire control and prevention equipment, information and communication technologies, and intelligent building concepts, more secure, comfortable, and convenient residential environments can be provided. For this study, ER Studio, SQL, and Visual Studio were used as tools to create a Web-base "fire-control surveillance, and management system." Fire control equipment was integrated into the building using the building information model (BIM). When a fire detector was triggered, a surveillance monitor could determine whether the warning was accurate and immediately identify information regarding the personnel relevant to the area on fire. Fire-fighters could then determine the fire conditions, as well as the location and types of relevant fireextinguishing tools through the network. Additionally, they can conduct fire control and rescue operations rapidly and effectively to protect the lives and property of residents.
\end{abstract}

Keywords: Fire control and management system, Building information modelling, Fire sensor, Monitor, Database.

\section{Introduction}

\subsection{Research background}

Taiwan is spatially limited, with the population primarily located in metropolitan areas. Tall buildings are increasingly constructed to increase living spaces and land usage. However, should a fire occur in these densely populated and large-scale buildings? It can result in significant losses of life and property. According to national fire statistics (from 2003 to June 10, 2012) provided by the National Fire Agency (Ministry of the Interior) [1], an average of approximately 4,803 fire incidents occur annually in Taiwan, with an approximate total of 4,310 deaths and/or injuries. The average annual direct property losses amount to approximately 1.7 billion NTD (new Taiwan dollar). These data show the severity of fire damage. Therefore, enhancing fire prevention methods and implementing rescue and escape operations during a fire is essential to reduce fire damage.

In the modern era, where information technology is rapidly developed, the combination of computer technology and fire and disaster prevention facilities and equipment is becoming a trend. Currently, the use of fire control equipment alone is gradually ceasing. This equipment is being replaced by highly integrated and multifunctional fire control safety equipment. Strategies for fire control have also progressed from passive prevention to the prompt detection of potential risk factors $s$ and establishment of disaster reduction measures [2].

\subsection{Research objectives and motivations}

A wide variety of specific decision support systems have been and can be built using Web environment [3]. Fire incidents cause significant losses of life and property; thus, prevention measures and rapid response strategies for disasters are extremely important. In this era of advancing information and communication technologies, fire control equipment with varying functions should be integrated in a single platform for management personnel to accurately determine the disaster conditions and effectively increase the efficiency of rescue operations. The building information model (BIM) has recently become a popular research topic among domestic and international scholars. In the past, rescue measures were confined to 2D models; however, by integrating a BIM environment and relevant fire control equipment, 3D fire prevention and monitoring systems can be established. Ultimately, the 3D models developed can provide more detailed building fire control information and effectively increase the efficiency of disaster prevention. The objectives of this study were as follows: 
1. To assess the recent effectiveness of the BIM model for construction engineering using a literature review.

2. To incorporate various building components and relevant fire control equipment into a model using BIM.

3. To analyze the system functions required for building fire control and surveillance systems and create a fire-control surveillance and management system using a Windows environment.

4. To examine and input actual cases to verify and adjust the system functions.

\section{Fire Control Surveillance System Analysis}

\subsection{Current fire control surveillance systems}

During high-rise building fires, the fire must be controlled long enough to provide sufficient time for occupant evacuation [4]. A fire control surveillance system comprises numerous equipment components. Song has developed a system which is able to monitor the environmental indexes of forest in real time for enhancing the efficiency of forest fire prevention and fire extinguishment [5]. Two essential testing methods for the firing sequence are presented by Jiang [6]. Any automation systems must enable all mechanical and electrical systems to work from a single building control point [7]. Fire detectors are linked to form a sensing network and connected to a control panel. The entire system is also connected to other fire prevention equipment in a building, including fire resistant roller shutters, fire sprinkler systems, and fume extraction systems. In the event of fire, the following processes occur: (1) the fire detector is triggered; (2) the system sends signals to the central control computer to activate the fire sprinkler system to extinguish the fire, close the fire resistant roller shutters to isolate the fire, and initiate the fume extraction system to enable personnel or people to escape; (3) evacuation notices are announced using a broadcast system; and (4) the fire brigade or department is notified and relevant fire control actions are conducted.

\subsection{Types of fire detectors}

Fire detectors are distributed in every corner of buildings. Postarnakov has developed the mechanism of the semiconductor sensor to detector for early warning of fire [8]. According to fire detection principles, fire is detected by locating the smoke, heat, or flames. Smoke and heat detection are the traditional methods. However, the disadvantage of these two methods is that the detectors can only recognize the presence of fire when the smoke or area temperature reaches a certain degree, delaying the reaction time.

The principle of ionization smoke detectors is to detect burning or combustion molecules in the air or materials produced by overheating plastics. When the detector detects these molecules, it activates an alarm to facilitate an immediate reaction and prevent fire outbreaks. Ionization detectors are primarily used in the clean rooms of high-tech factories. Experiments were conducted in a full-scale model office equipped with movable and fixed fire loads to explore the influence of ignition source conditions on smoke detector and sprinkler actuation [9]. To manage security level of information system, organizations must select security practices first, and then apply them according to security level [10].

Photoelectric ionization smoke detectors are used in tall and spacious rooms, such as those in factories and hypermarkets. The detector emits infrared light beams, and when smoke is generated, the light beams scatter and trigger an alarm. This type of detector overcomes the problem of detectors only being activated when the smoke density reaches a certain degree, which delays the alarm response.

\subsection{Control panel}

Building automation is realized by means of a real time information system for supervision and control of central heating, electrical lighting, access and energy consumption [11]. New build properties should take into account a fire strategy within their design [12]. The control panel functions similarly to the human brain. Puttock recommended fire alarm system should connected remotely to an alarm receiving center with the ability to alert keyholders and the fire brigade as required [13] When the detector is triggered, it sends signals to the control panel, which then executes follow-up actions, such as notifying fire units, activating roller shutters and fume extraction systems, and broadcasting evacuation warnings. Addressable fire alarm devices and control 
panels meets the requirements for the electrical supervision of field devices and it provides the means of identifying the point in a building where an alarm has been initially activated [14] Fire alarm control panels can be divided into two types, the P-type and the R-type. The Ptype comprises traditional control panels that have simpler detector functions and signal transmissions. These control panels form a single loop on one floor of a building. However, only signals transmitted from the single loop can be received, and the exact location that triggered the detector cannot be determined.

The R-type control panel detectors consist of addressable devices, and a number of detectors and repeaters are connected. When the repeaters send signals to the control panel, the detector triggered can be identified.

\subsection{Fire control surveillance system}

HVAC system is complex and available sensor information as its fault detection is insufficient [15]. Kostis have presented a control system analysis and design educational tool built on the MATLAB platform which is very easy to use and does not require the knowledge of a sophisticated computer language [16]. The equipments' full-time data record, including the most equipments operating state information, can give helps to the capability test and fault maintenance [17]. The representing node and matrix are difficult to understand the relationship between network nodes [18]. Two types of fire control surveillance software are available on the market: (1) software for monitoring building facilities and equipment, for example, identifying the location where a detector was triggered and determining the status of water supplies for fire prevention, power supplies, fire alarms, broadcasting systems and equipment, beepers and buzzers, and fume extraction systems. This type of software focuses on the functional status and control of various equipment in the building. (2) Software oriented toward controlling an entire building space; this type of system displays the location where a detector is triggered and the status of all equipment on the building plan.

\section{Introducing BIM}

\subsection{Analysis of current BIM status}

Use of the BIM is increasing and developing worldwide. In recent years, Taiwan has incorporated the BIM in construction processes; therefore, many cases are currently presenting the results of BIM-incorporated construction projects. Besides using the BIM in the planning, design, and construction stages of a construction life cycle, its function can be extended into the subsequent usage and maintenance stages.

The BIM is primarily employed in the designing process for quantification calculation and validation. The introduction of Ecotect software by Autodesk facilitates the analysis of building functions and environments during the planning stage. During the operations process, the BIM can be applied in the building maintenance and usage stages. If defects caused by construction negligence are found, BIM data can be used to determine the source of the construction negligence.

Within the life cycle of a building, approximately 2 to 3 years is spent designing and completing building constructions. After completion, buildings are then used for 30 to 40 years, or occasionally for even longer than 50 years. For the majority of their life cycles, buildings are in operational use. If the functions of the BIM can be extended to the building operations, maintenance, and management stages, the value of this model can be further demonstrated. The fire-control surveillance and management software developed in this study can be applied during the operational stage.

\subsection{Component definitions}

Objects within the BIM model can produce detailed definitions and annotations for each building component. Furthermore, the model establishes component properties to define the restrictions and relationships between objects at the site and other components. The technical building regulations regarding the time effectiveness of fire resistant walls include definitions concerning the fire resistance levels of different types of walls. The definition of a certain wall can be applied to walls of an identical type throughout the model. 


\subsection{Fire prevention subdivisions}

The Water Cube was developed by investigating several factors for the buildings in the event of a fire [19]. Building with complex geometries should be modeled by cuboids with their edges right on the computational grids and having important physical factors [20]. According to Building Technical Regulations, Article 79, buildings with a total floor area greater than $1500 \mathrm{~m}^{2}$ should build walls with 1$\mathrm{h}$ or more fire prevention effectiveness every $1500 \mathrm{~m}^{2}$, and fire prevention equipment (exits and windows) should be subdivided and segmented. This study employed the screening function in Autodesk Revit software and chose walls with 1-h or more fire prevention effectiveness in a building (Figure 1).

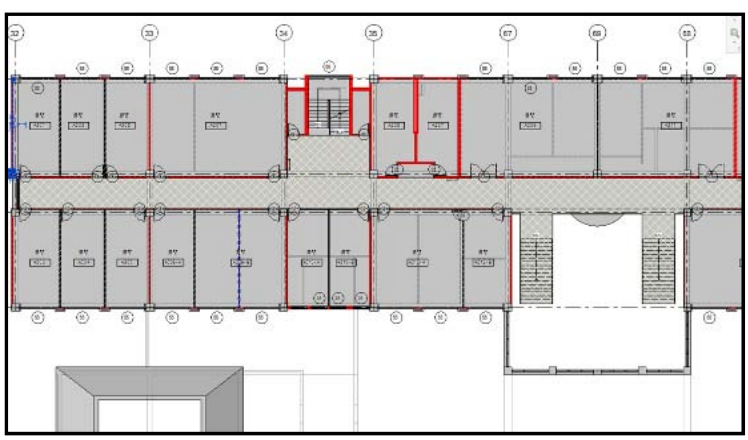

Figure 1. Fire prevention subdivisions of a building

\subsection{Spatial subdivisions}

Building structures (from large to small) were separated into the following four categories: buildings, floors, zones, and rooms. Monitoring units were established according to the building floor patterns, and zones were separated based on the relationships between locations, emergency entrances and exits, and escape routes. In the diagram shown in Figure 2, the green circles represent the emergency entrances and exits for that floor, the yellow lines denote the zones, and the areas highlighted with blue lines are assembly zones that form part of the escape route. If a fire occurs in the blue regions, the escape routes will be blocked. Furthermore, the area near the staircase also affects the escape routes of people on the next floor up.

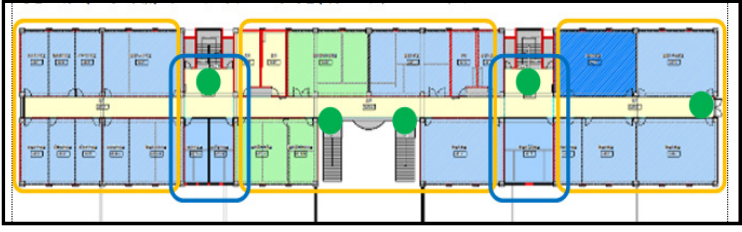

Figure 2. Diagram of the separated floor zones

\section{Conducting a Case Study}

\subsection{Inputting building spatial data}

For this study, the Architecture College of Chung Hua University was used as an example, and the building was inputted into the model software according to actual dimensions. Figure 3 shows the 3D structure of the building.

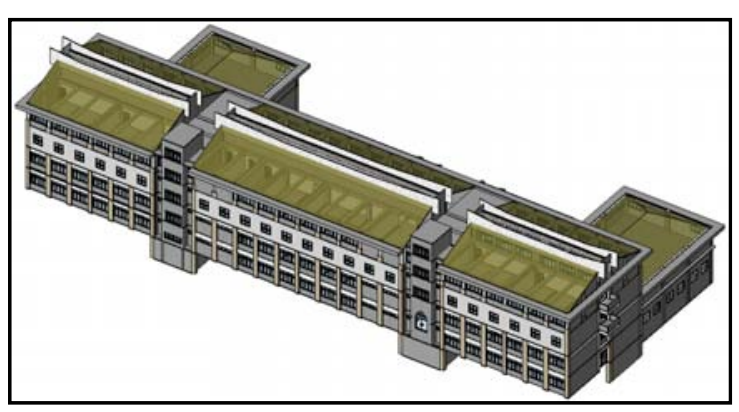

Figure 3. 3D view of Chung Hua University's Architecture College

\subsection{Modeling of fire control equipment}

Because the fire control equipment group was not included in the Autodesk Revit software, detectors, surveillance devices, and fire hydrant groups were created for the model. Additionally, the required parameter values were inputted and the information of various fire prevention equipment was also inputted after the varying groups were formed. When creating the detector groups, the working range could be converted into parameters, and then entered into the group model. This method was used to calculate the working ranges of the detectors and identify the presence of blind spots in certain spaces.

Figure 4 shows the front and bottom view of the detector group. For a defined ceiling height, the working range for the corresponding plane of the detector was depicted as a circular shape. By entering the statement formula into Revit software, the formula can be calculated according to the input conditions. The following statement structures were used in this study:

IF (<condition $>$, < result-if-true $>$, $<$ result-if-false $>$ )

where <condition> denotes a certain condition, and an expression for <result-if-true> is executed if the condition is true. Conversely, if the condition is false, an expression for $<$ resultif-false $>$ is executed.

After inputting the parameters, the setting of the object was complete, and the BIM model 
could automatically calculate the working radius of the detectors according to the ceiling height for the established location (Figure 5).
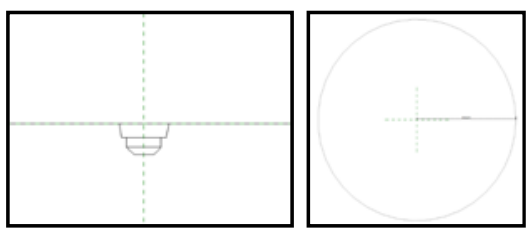

Figure 4. Detector group

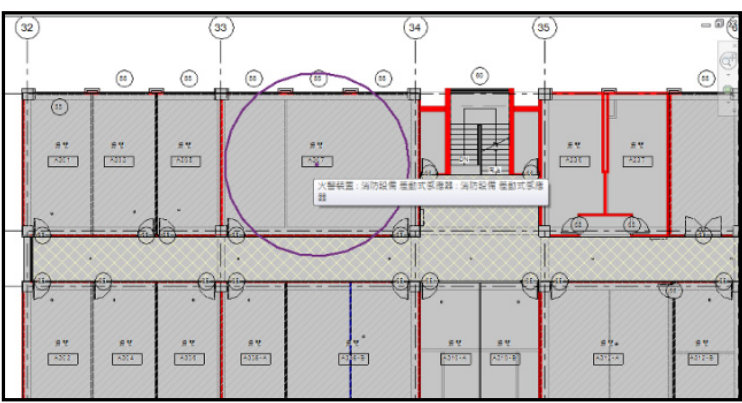

Figure 5. Working range of the detectors

\subsection{Creating the database}

For this study, ER Studio software was employed to create database structures and establish relationships and constraints between the data tables. Subsequently, the logical model was transformed into a physical model (Figure 6 ), and the database structure was incorporated in the SQL server via ODBC connections (Figure 7).

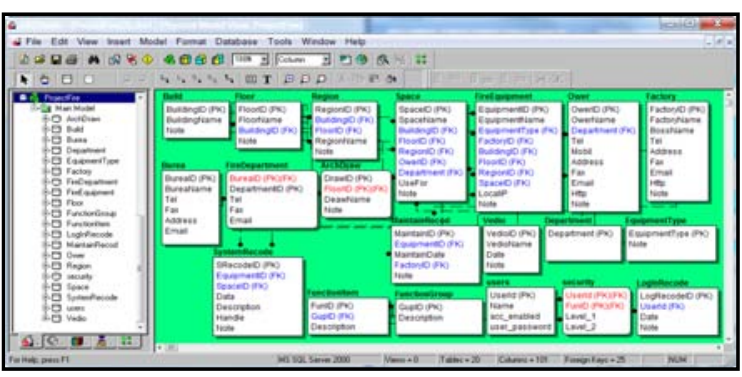

Figure 6. ER-Morel Logical Model

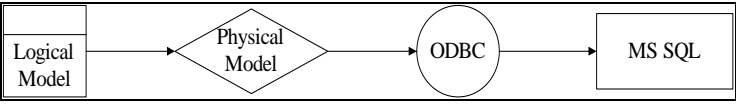

Figure 7. Flowchart of data conversion

\subsection{BIM data conversion}

The complexity of the modeling and repetitiveness of the information conversion owing to different disciplines were illustrated by various representation of building components [21]. Various commercial CAD/ CAE software applications are purchased by design firms for multi-disciplinary design tasks. However, researches on integration and interoperability are seldom considered [22]. The original elements (buildings and fire control equipment) developed in the BIM model in this study can be exported to disaster prevention management systems. This feature eliminates repetitive input work and avoids human errors. The import process was as follows:

1. Convert data using ODBC.

With Revit software, create a link to the database using the"ODBC" option in the "Export" menu.

2. Import the data to the database as a text file (.txt)

Using Revit, when the itemized list for required data is created, select "Export" $\rightarrow$ "Report" $\rightarrow$ "Export itemized list.” When saving, the system will provide a dialog box regarding the location of the file to be saved and the text file specifications. When the text file is exported, use the Import and Export Wizard to import the text file content to the SQL server.

\section{Introduction to System Functions}

In this study, the system was divided into the following four modules: the building fire control surveillance module, fire control equipment data module, spatial usage data module, and common data module.

\subsection{The building fire control surveillance module}

Dossick has examined the use of BIM technologies for mechanical, electrical, plumbing, and fire life safety systems coordination and how the introduction of BIM influences collaboration and communication [23]. This module in this study is the core of the system. The interface was divided into the following three sections: "3D BIM," "alarm location data," and "floor-by-floor monitor location map" as shown in Figure 8.

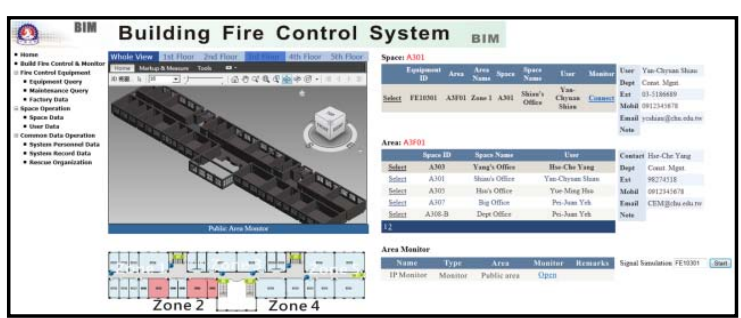

Figure 8. Screenshot of the building fire control surveillance function 


\section{3D BIM}

This module enables management personnel to determine building structures through 3D images. They can observe the interior of buildings using the panning, zooming, and rotating functions (Figure 9). This module can also examine objects, such as fire hoses(Figure 10), in the model using the internal functions of DWF View. Additionally, various types of components can be selected, and all items belonging to the type selected are highlighted in color in the model after selection (Figure 11). This function enables firefighters to determine the location of important fire control equipment, such as exits or escape routes and fire hydrants. If the selected component is small, the system magnifies the view for users to examine the object more easily.

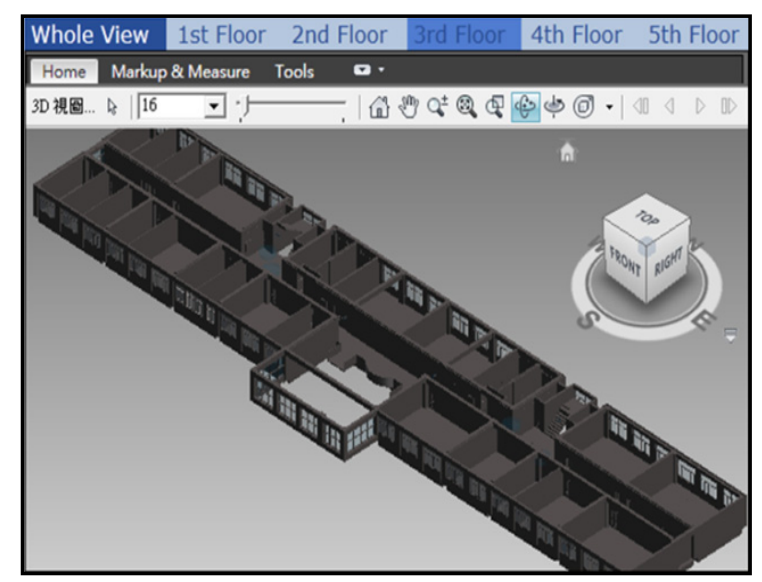

Figure 9. Screenshot using the DWF View rotational model

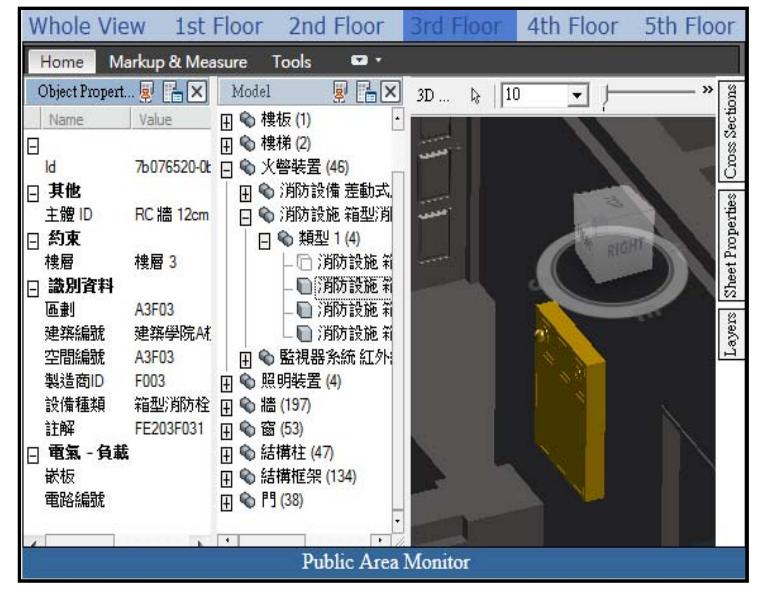

Figure 10. Screenshot of BIM component data

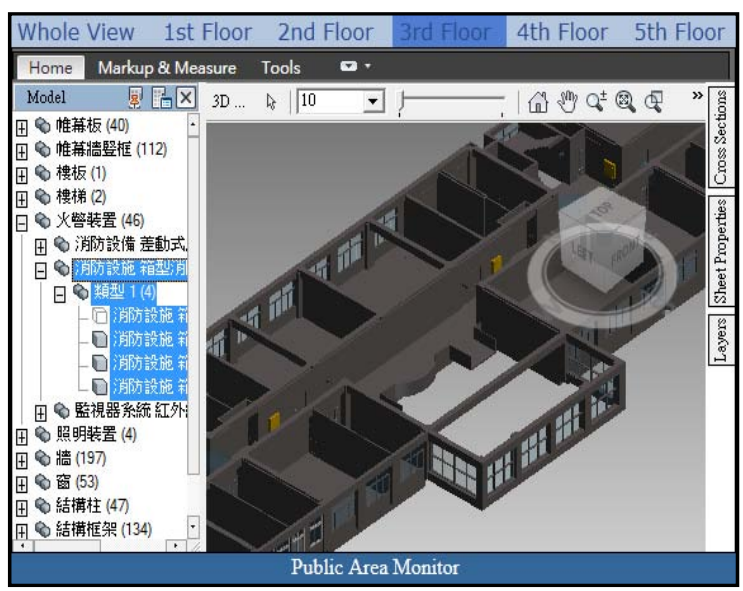

Figure 11. Screenshot of components selected in the BIM list

\section{Alarm Location Data}

When the fire control panel transmits signals from the detector to the system, the system searches the database for spatial and zone information according to the serial number of the detector. Information regarding the rooms covered by a detector and the personnel using the detector is also shown on the screen (Figure 12). Management personnel can select the "open screen" option to view the monitor in that location and obtain an understanding of the situation within the affected space (Figure 13). Once the occurrence of a fire is verified, management personnel activate relevant fire control measures, such as personnel evacuation and extinguishing the fire. If the signal was erroneous, personnel can investigate the alarm device and wiring and identify the problem.

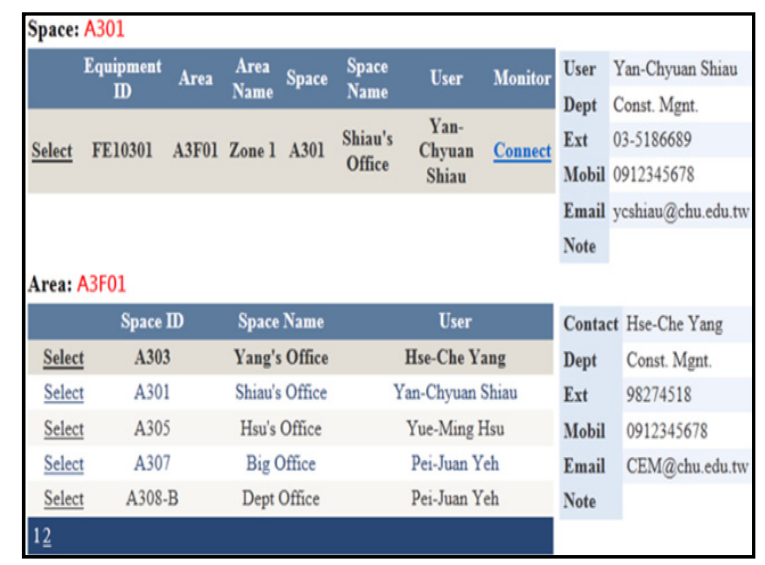

Figure 12. Screenshot of the surveillance system 


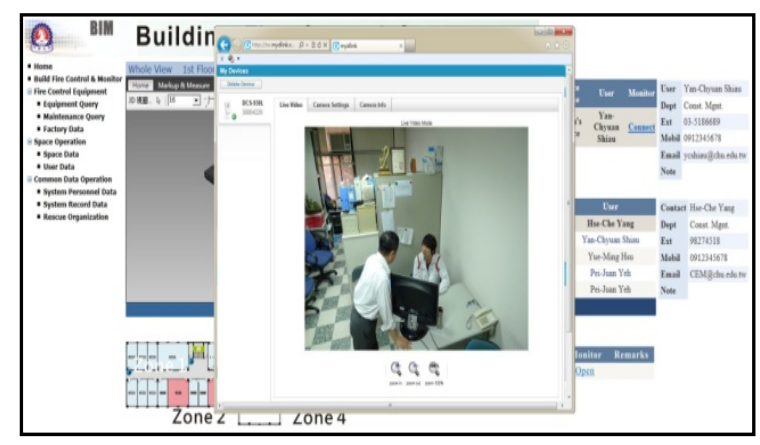

Figure 13. Screenshot when opening the monitor view

\section{Floor-By-Floor Monitor Location Map}

This location map shows the locations for monitors installed in public areas on each floor. Various monitor icons can be selected directly to examine the condition of each floor through the monitors. The blue circle icons displayed in Figure 14, denote the locations of monitors. Selection of the icon opens the video image from that camera.

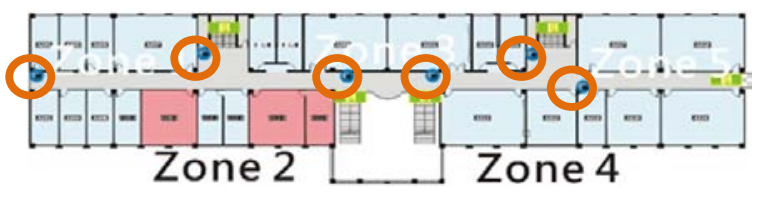

Figure 14. Image of the monitor locations (floor level)

\subsection{Fire control equipment data module}

This module primarily provides maintenance and inquiry functions regarding fire control equipment. This module includes equipment data maintenance, manufacturer information maintenance, and maintenance record preservation.

\section{Equipment data maintenance}

This page is divided into selection functions and information displays. The selection function selects and searches data according to floor, zone, space, and equipment types. Inquiries are made by selecting items from a drop-down menu (zones can be selected within floors, spaces can be selected within zones, and equipment can be selected within spaces). If the box before a menu is ticked, the information selected for that menu can be used as the selection condition. The selection results are then displayed in the lower data display area (Figure 15). A cross-type function was used for this selection method. For example, if only the "floor" box is ticked, all the equipment on that floor will be displayed. However, if the "zone" box was also ticked, the equipment for the selected zone in the selected floor would be displayed. The process is similar for other selection patterns (Figure 16).

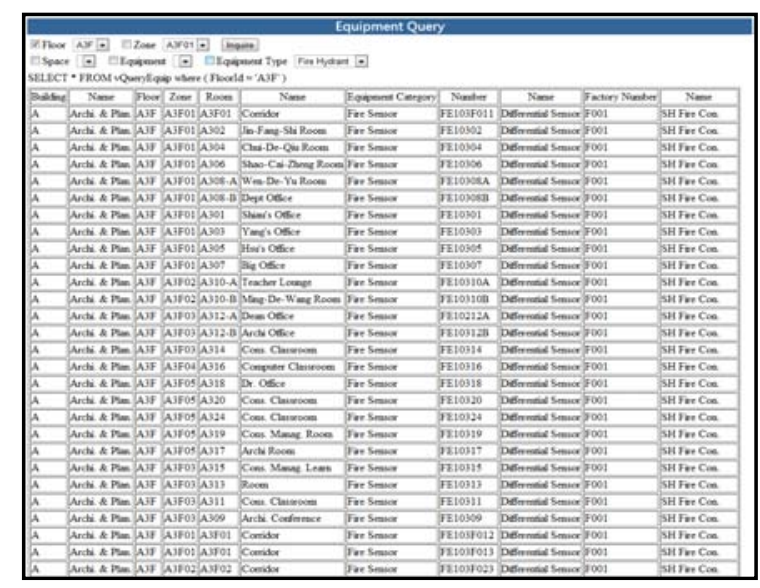

Figure 15. Screenshot of an equipment information search

\section{Manufacturer Information Maintenance}

This page provides for the maintenance of and inquiry into manufacturers' information, including manufacturer serial numbers, company or manufacturer name, name of responsible contact, contact number, address, fax number, e-mail address, Web site address, and other additional notes.

\section{Maintenance Record Preservation}

This page provides preservation for and inquiry into relevant maintenance records, such as maintenance serial numbers, dates, equipment manufacturer, equipment name and location, and additional comments (Figure 17).
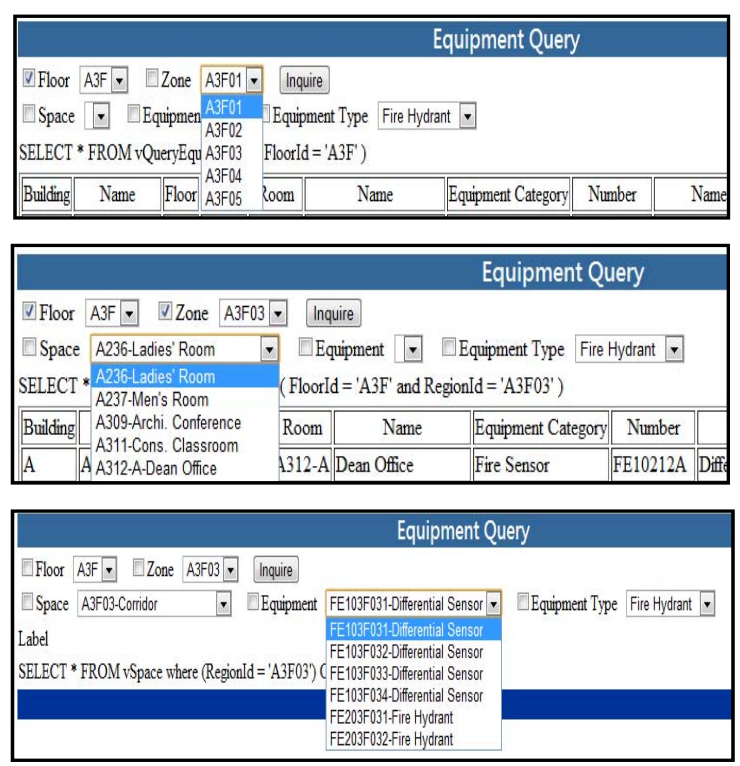

Figure 16. Screenshot of the related drop-down menus 


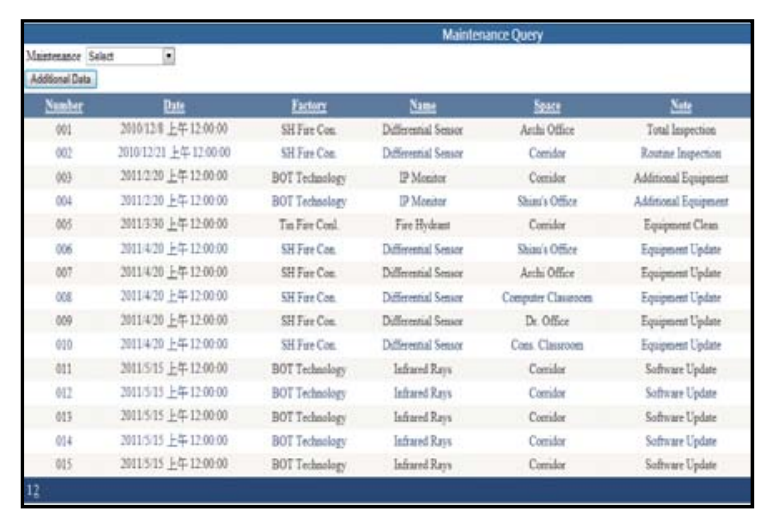

Figure 17. Screenshot of inquiries for maintenance records

\subsection{Spatial usage data module}

This module provides maintenance for relevant space and user data to provide for preservation and inquiry of this data.

1. Spatial Data Maintenance

This page provides maintenance of inquiry into the name and relevant information of the space on a certain floor and in a specific zone (Figure 18).

\section{User Data Maintenance}

This page provides maintenance for and inquiry into relevant user information, including names, departments, telephone extension numbers, mobile phone numbers, and e-mail addresses (Figure 19).

\subsection{Common data module}

The common data module performs the following functions:

1. System Usernames Data Maintenance

This page provides maintenance for system username information, including usernames, passwords, and users' use restrictions.

2. System Records Maintenance

This page is used to record system incident data, such as the serial number of incidents, equipment, space, dates, event or incident descriptions, processing status, and additional comments.

3. Fire Unit Information

This page provides maintenance for information regarding fire and disaster relief units that have jurisdiction over the building, including the contact details for disaster relief personnel and relevant units.

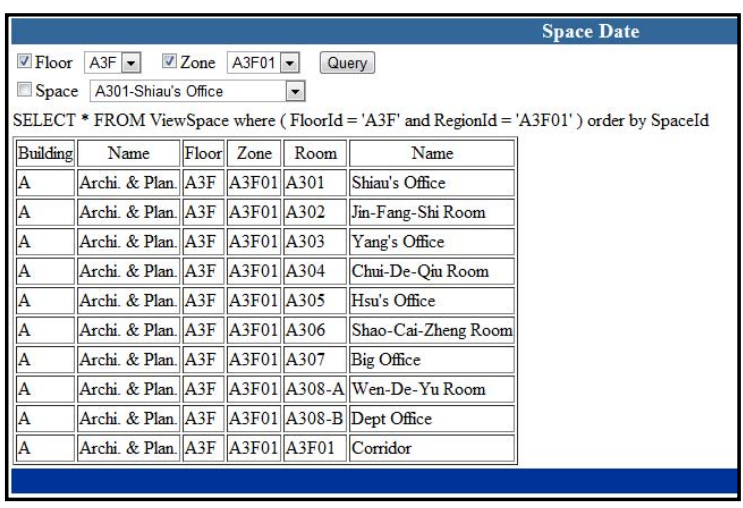

Figure 18. Screenshot of inquiries for spatial data

\begin{tabular}{|c|c|c|c|c|c|c|c|}
\hline 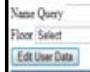 & & $m=1500$ & & & & & \\
\hline $\operatorname{sen} \frac{12}{\sin }$ & & & Der & IVI & Dmatant & Intan & manther \\
\hline 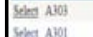 & त्रा & 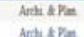 & 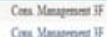 & Burer & $\cos V_{m e t}$ & sizosin & 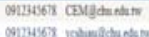 \\
\hline & Nap & Artakpe & Com & $\begin{aligned} y \\
y\end{aligned}$ & $\operatorname{cosen} x(x)$ & Casiness & 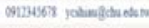 \\
\hline Sime $n=5$ & arom & Artitive & Com Xesprom if & Yonseraflis & $\operatorname{cosen} x_{0 x}$ & s2zssi & 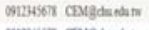 \\
\hline 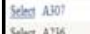 & A A Fol & Ant the & Cot Mensem if & & 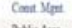 & 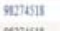 & 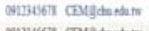 \\
\hline & A & 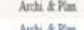 & Cats & 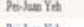 & Pate hert & 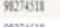 & 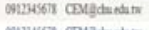 \\
\hline & 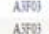 & 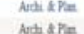 & 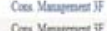 & 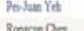 & Pate An & 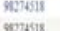 & 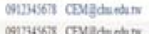 \\
\hline sing Aill & A & Antis the & 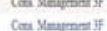 & 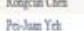 & $\cos ^{2} x_{m}$ & & 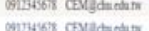 \\
\hline Sous & AFo & Artat the & $\mathrm{C}=\mathrm{M}$ Nerpen if & Ponsert & Com & & 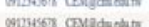 \\
\hline 然 & 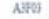 & Artat $A=$ & Creat Mentrom if & 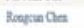 & $\operatorname{cosen} x_{m}$ & หระเа & 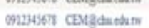 \\
\hline 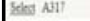 & A A B W & Antat A $P=$ & 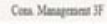 & $P_{t a t}=\mathrm{Y}_{\mathrm{t}}$ & & язи & 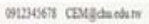 \\
\hline A Al9 & Nases & Natikn= & $\cos F$ & 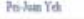 & $\cos x_{0=1}$ & 9:345it & 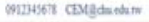 \\
\hline & AFP & Note the & 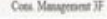 & Posher $Y_{d}$ & $\operatorname{cosen} x(x)=$ & 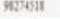 & 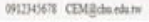 \\
\hline & Nins & Nathere & & 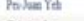 & $\cos x x_{0}+4$ & 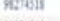 & 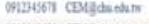 \\
\hline DNI & 年 & 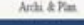 & & & $\cos x x^{\circ} x$ & & Maghenter \\
\hline
\end{tabular}

Figure 19. Screenshot of maintenance for user information

\section{Conclusion}

For this study, the BIM model, an SQL server, and a Windows environment were used to develop a fire-control surveillance and management system. Additionally, actual cases were examined to verify the system functions. Following numerous corrections, debugging incidents, and revisions, the system developed in this study functioned successfully. Based on the results of this study, the following conclusions have been inferred:

1. Intelligent building concepts have become a trend for future residences. By integrating information and communication technologies into building equipment, building equipment can be automatically controlled while interacting with residents. Consequently, more convenient, comfortable, and secure living environments can be provided.

2. In this study, a fire-control surveillance and management system was developed by incorporating fire prevention equipment into the building spatial model. With this system, when a detector is triggered, relevant monitors can be viewed immediately to rapidly determine the actual 
situation and verify the authenticity of the fire alarm. This function prevents false alarms that cause panic and distress and fatigue to relevant personnel.

3. The Web-base fire-control surveillance and management software developed in this study does not only transmit relevant fire control information in one direction. Firefighters and rescue workers can also access the system through the network to assess the current situation and obtain relevant information, such as the fire ignition point and the location and content of fire control equipment. The BIM model has replaced the traditional 2D rescue operation images to prevent mistakes when images are interpreted incorrectly.

4. The automatic conversion of building component data in the BIM model can increase the accuracy of the database. This function prevents repeated information input and establishment and human errors. Furthermore, the system increases the efficiency of equipment and space management in buildings and simplifies follow-up maintenance and space management.

\section{REFERENCES}

1. FIRE AGENCY, MINISTRY OF THE INTERIOR, National Statistic Data Table of the Number of Fire Accident, the Origin and Cause of Fires and the Loss Due to Fire Accident.

2. HUANF, C. M., Initiate Industrial Revolution for Fire Prevention: Redirection and Renovation of the Safety Industry, e-Generation Safety and Disaster Prevention Conference National Fire Agency, Ministry of the Interior and Economic Daily News, 2007.

3. POWER, D. J., S. KAPARTHI, Building Web-based Decision Support Systems, Studies in Informatics and Control, vol. 11, no. 4, 2002, pp. 291-302.

4. CHU, Y., H. ZHANG, R. YANG, T. CHEN, Building Fire Smoke Control Strategies Simulation using Fire and Evacuation Information, Journal of Tsinghua University (Science and Technology), vol. 50, no. 8, 2010, pp. 1158-1162.
5. SONG, Z., N. CHEN, D. LI, Application of ZigBee Wireless Sensor Technology in Forest Conflagration Surveillance, Process Automation Instrumentation, vol. 32, no. 4, 2011, pp. 50-52.

6. JIANG, C. J., Testing of Functions of Complex Systems based on Synchronous Composition Nets, Studies in Informatics and Control, vol. 9, no. 4, 2000, pp. 321-328.

7. KILIUS, S., A. VALINEVICIUS, Analysis of Home Information Network Technologies, Elektronika ir Elektrotechnika, no. 2, 2005, pp. 30-33.

8. POSTARNAKOV, S. V., I. V. SERDYUK, I. A. TARATYN, Sensors Unified Security Systems Fire Detectors, Early Warning Fire, Problems of Radioelectronics, no. 1, 2012, pp. 123-131.

9. LAI, C. M., K. J. CHEN, C. J. CHEN, C. T. TZENG, T. H. LIN, Influence of Fire Ignition Locations on the Actuation of Smoke Detectors and Wet-Type Sprinklers in a Furnished Office, Building and Environment, vol. 45, no. 6, 2010, pp. 1448-1457.

10. KIM, T. H., Definition of Security Practices in STP for SLMM, International Journal of Hybrid Information Technology, vol. 1, no. 1, 2008, pp. 111-118.

11. HARTESCU, F., C. DANILOV, M. COSMA, L. NEDELCU, Real Time Tools for Building Automation Applications Generator, Studies in Informatics and Control, vol. 6, no. 2, 1997, pp. 215-218.

12. MOSELEY, T., An Effective Fire System Will Help Save Lives, Building Engineer, vol. 83, no. 2, 2008, pp. 24-25.

13. PUTTOCK, R., How to Keep Your Fire Detection System Healthy, Building Engineer, vol. 85, no. 10, 2010, pp. 18-19.

14. GOODYEAR, D., Addressable Fire Alarms, Canadian Consulting Engineer, vol. 47, no. 5, 2006, pp. 45-48.

15. MYASAKA, F., YAMASAKI, T., YUMOTO, M., OHKAWA, T., KOMODA, N., Fault Detection and Diagnosis for HVAC Systems using Stochastic Qualitative Reasoning, Studies in 
Informatics and Control, vol. 10, no. 3, 2001, pp. 189-207.

16. KOSTIS, D. L., E. S. TZAFESTAS, S. G. TZAFESTAS, A MATLAB-based

Graphical Toolbox for Control System Analysis and Design Education, Studies in Informatics and Control, vol. 8, no. 3, 1999, pp. 209-219.

17. YANG, J., W. JIANG, The Design and Realization of the Fire Control Radar Operating Statusy Surveillance Recorder, Journal of Projectiles, Rockets, Missiles and Guidance, vol. 30, no. 2, 2010, pp. 221-228.

18. PARK, S., J. KWON, Y. LEE, S. R. LEE, Study of Visualization for Data Network Node, International Journal of Hybrid Information Technology, vol. 5, no. 2, 2012, pp. 89-94.

19. FOLEY, M., Pools Winner, Fire Prevention and Fire Engineers Journals, 2006.
20. WU, W. Y., Z. R. GAO, A. Z. REN, Physically-based Model for Fire Scenario in FDS, Journal of System Simulation, vol. 17, no. 8, 2005, pp. 1800-1802.

21. LIU, Z., Y. LI, X. LU, H. ZHANG, BIMbased Integrated Information Framework for Architectural and Structural Design Model, Journal of Tongji University (Natural Science), vol. 38, no. 7, 2010, pp. 948-953.

22. QIN, L., X. Y. DENG, X. L. LIU, Industry Foundation Classes based Integration of Architectural Design and Structural Analysis, Journal of Shanghai Jiaotong University (Science), vol. 16, no. 1, 2011, pp. 83-90.

23. DOSSICK, C. S., G. NEFF, Organizational Divisions in BIMenabled Commercial Construction, Journal of Construction Engineering and Management, vol. 136, no. 4, 2010, pp. 459-467. 